University of St. Thomas, Minnesota

UST Research Online

2005

School Social Workers' Evaluation of Group Work Practices

Kendra J. Garrett

University of St.Thomas, Minnesota, KJGARRETT@stthomas.edu

Follow this and additional works at: https://ir.stthomas.edu/ssw_pub

Part of the Clinical and Medical Social Work Commons, and the Social Work Commons

This Article is brought to you for free and open access by the School of Social Work at UST Research Online. It has been accepted for inclusion in Social Work Faculty/Staff Publications by an authorized administrator of UST

Research Online. For more information, please contact asle4660@stthomas.edu. 


\section{School Social Workers' Evaluation of Group Work Practices \\ Kendra Garrett}

School social workers frequently work with students in small groups. Evaluation of group work outcomes may be even more complicated than evaluating individual practice successes because of the complexity of group work. Not only are there several clients to monitor simultaneously, the group itself becomes an additional client (Shulman, 1992) that is worthy of evaluation as well. To offer practitioners a resource to call on when assessing the progress of group work, this study drew on the experiences of 54 school social workers, all members of the School Social Workers' Association of America. The social workers were surveyed in an attempt to document up-to-date information about the nature of school social workers' evaluation of their group work practice, and therefore determine how effectively they are fulfilling the ethical and professional mandate to evaluate practice effectiveness.

Specifically, this study was designed to shed light on: the extent to which goals were being identified and monitored for individual members and for the group as a whole, the kinds of goals being identified, how individual and group goals were monitored, and the kinds of records school social workers use to keep track of their group work practice.

Group work becomes more meaningful when it is viewed with a holistic perspective. Social workers, therefore, must try to give equal weight to all aspects of the group's functioning, as opposed to focusing solely on outcomes. Northern and Kurland (2001) echoed Sabatino and Timberlake's (1999) plea to attend to group processes as well as to the outcomes of the intervention to try to determine what causes member 


\section{Group Outcomes 2}

growth and change. Toseland and Rivas (2001) suggested that the social worker assess both individual members and the group as a whole, placing an emphasis on monitoring both member outcomes and group processes.

A school social worker can monitor the outcomes of group work interventions for individual members by consulting objective data, such as rates of vandalism or attendance records; using tests of knowledge, such as standardized achievement or knowledge-based tests (Allen-Meares, Washington, \& Welsh, 2000); observing member behavior in the group through structured observations or during role-play simulations (Rose, 1984); using goal-attainment scales, in which students and social workers collaborate to identify possible outcomes ranging from "unacceptable" to "more than the expected" levels, (Allen-Meares et al.; Toseland \& Rivas, 2001); asking group members to complete inventories or rating scales (Rose); developing single-system research designs; analyzing group outputs or products (Toseland \& Rivas); and measuring member satisfaction (Northern \& Kurland, 2001). Alternatively, members may monitor their own progress toward goals by self-recording their thoughts and behaviors or progress toward completion of contracts agreed on in early stages of the group (Toseland \& Rivas) through daily logs or structured diaries. Collateral contacts such as family members or teachers can also give feedback on the accomplishment of member goals outside the group (Rose).

It is also important for school socials workers embarking on group work to consider the limitations of measurement in any monitoring plan. Rose (1984) cautioned that an emphasis on practice evaluation through measurement alone limits practice goals to problems that can be measured. In other words, social workers should supplement 


\section{Group Outcomes 3}

measurement with subjective impressions, professional intuition, and unstructured observation (Feldman, 1985).

Monitoring group dynamics is perhaps more complex than measuring individual progress. Several measures have been developed to operationalize various group dynamics, including member helpfulness, self-disclosure, closeness, task orientation, control of group sessions, conflict, anxiety, anger, and level of productivity (O'Brien, Korchynsky, Fabrizio, McGrath, \& Swank, 1999), engagement, avoidance, cohesion, (Rice, 2001), instillation of hope, altruism, interpersonal learning, and universality (Yalom, 1995). McCullough and Koontz (1993) developed an instrument to assess group trust, self-disclosure, and listening in children's groups. Kaminer and colleagues (1998) created a scale to measure interpersonal learning, expression of emotion, exploration of feelings, and "here-and-now" focus for use in groups with adolescents. Toseland and Rivas (2001) also suggested monitoring the frequency and direction of positive and negative member interactions and using sociometric measures of members' attraction to each other. There has been little empirical evidence, however, that the development of positive group processes is associated with positive group outcomes (Kaminer et al.; Magen \& Glajchen, 1999; O’Brien et al.; Rice).

Qualitative approaches may provide clearer descriptions of group member interactions and help determine what is effective in a group intervention. A process recording, in which the worker writes everything that happened in a group, although time consuming, can be very helpful in identifying group processes. When process recordings are not possible, frequent summary recordings can chart member progress. Social workers should make every effort to ensure that these summary recordings identify the 


\section{Group Outcomes 4}

group processes that led to (or interfered with) successful goal attainment in the group. It is important to note, however, that group recordings may not be completely confidential and multidisciplinary team members, family, lawyers, and courts may have access to the records (Northern \& Kurland, 2001). Group case studies also offer an opportunity to analyze treatment groups. A case study goes beyond process recording to include observation, ethnographic descriptions, member interviews, analysis of content of group recordings, observations of the group, focus group interviews with members, or case comparisons, noting similarities and differences between groups (Toseland \& Rivas, 2001).

Although school social work and social group work literature provide numerous recommendations to school social workers about why and how practice should be evaluated, there is little information available about the nature and extent of outcome evaluation in actual school social work practice. This study begins to bridge that gap. I hope that theory and practice may be brought closer together. The goal of this study, then, was to identify ways school social workers monitor and evaluate their school-based group work practice. The reported results are a part of a larger, more comprehensive survey of social group work practice in schools.

$<$ ah $>$ Method

The survey in this study was a mixture of 53 short-answer, multiple-choice, and checklist quantitative questions and eight open-ended, qualitative questions. The quantitative questions asked respondents about group recording, communication, control issues, and goal setting for individual members and for groups. These results were analyzed using SPSS 10 for Macintosh. Open-ended qualitative questions asked respondents to describe 
group and individual goals, development of mutual aid and cooperation among members, and the way they monitor outcomes. Qualitative responses were analyzed without the aid of software using open coding and grouping responses by themes. I listed responses to each question and assigned category codes to responses, then reanalyzed the categories to be certain they fit together, rearranging categories as needed.

$<$ bh $>$ Sample

Surveys were mailed to a sample taken from a randomly generated list of 960 members of the School Social Workers' Association of America during the summer of 2002. A systematic random sample of 313 of these school social workers was chosen by using every third address label sheet. Sixty-seven surveys were returned, but 13 of these were discarded because the respondents indicated that they were in supervisory positions or no longer practicing. No follow-up procedure or reminder mailings were used. The remaining 54 surveys were completed by social workers who were in direct practice in a school setting, creating a usable response rate of 17 percent.

Because sample response was low, it would probably be better to present the numbers rather than the percentages. Of the respondents, 94.4 percent $(n=51 ? ? ?)$ had MSW degrees, 1.9 percent $(n=1)$ had a BSW degree, and 3.7 percent $(n=2)$ had doctoral degrees. Respondents averaged 13.11 years experience in school settings. They served students of all ages, and many practiced in several settings simultaneously: 33 percent $(n=18)$ worked in preschool settings, 70 percent $(n=38)$ in elementary schools, 43 percent $(n=23)$ in middle schools or junior high schools, 33 percent $(n=18)$ in high schools, and 20 percent $(n=11)$ in alternative settings.

$<$ bh $>$ Goal Setting and Recording 


\section{Group Outcomes 6}

Analyses of variance and chi-square analyses were used to determine whether there were differences in use of group or individual goals by the hypothesized independent variables of age level of students served or by funding source. Neither independent variable had an effect on monitoring of individual or group goals or the kinds of record keeping (addressed in the quantitative questions) used. Respondents indicated overwhelmingly on a yes/no question that they have goals for individual group members (74.1 percent, $\mathrm{n}=$ 40)). In a qualitative follow-up question, they gave many examples of goals set for student members of groups. The goals fell into five categories, in order of frequency: (1) improved social skills (44 examples), (2) greater affective skills (seven examples), (3) better behavior management (seven examples), (4) improved school-competency skills such as attendance or academics (six examples), and (5) enhanced coping skills (six examples).

Within the social-skill category, the most frequently cited goal was participating in a conversation or discussion, followed by assertiveness, making eye contact, and making "I statements." There were several other examples ranging from sharing to introducing oneself. Affective goals included identifying and verbalizing emotions and managing anger. Behavioral goals included decreasing fighting, blurting out, and rudeness. School-competency skill goals included turning in homework, better attendance rates, problem solving, and persistence in reading. Coping goals included increasing selfesteem, coping with stress, and self-calming.

The specificity of the goals varied greatly. Some were explicit and had, at least implied, measurements. For example, "participate 8 out of 10 times in the group activity without complaining," and "complete homework assignment on time," and "ask a peer to 


\section{Group Outcomes 7}

play at recess." Other goals were stated in less overtly measurable terms: "reducing verbal rudeness with peers," "participating in projects," and "better social adjustment." It was not always clear where or by whom the goals were to be measured. Of the goal examples given, 15 (approximately 21 percent) were goals that could be measured inside the group, and 13 (19 percent) of the goals needed to be measured outside the group.

Respondents also indicated overwhelmingly (72 percent, $n=39)$ in a closedended question that they have goals for their groups. In the qualitative follow-up question, they listed 49 examples of group goals, but the vast majority of the responses (33) were actually individual goals that members held in common. Examples of such goals were: "increase social skills," "identify feelings," "stay out of the principal's office for discipline purposes," and anger management. Many of the goals referred to group learning. For example, group members would learn about their attention deficit disorder, prevention of sexually transmitted diseases, inappropriate touching, or the steps necessary to play a game.

Five respondents mentioned group norms as group goals. These included confidentiality, respect, avoidance of insults, remaining quiet when others are talking, and completing topics on a schedule. Nine of the school social workers reported group goals that referred to interaction among members. These included goals that members would improve in social interaction, cooperate, work together to solve problems, focus on others, help each other, increase cohesiveness, and converse, with members listening to each other. One group interaction goal was negatively stated, indicating that the group would be successful if they could play a card game "without insults, cheating, or poor sportsmanship." 


\section{Group Outcomes 8}

Respondents identified those involved in the goal setting by use of a check-off list of potential participants. Multiple responses were acceptable. They indicated that goals are developed by a number of different people in the school setting. Of the respondents 43.0 percent $(n=23)$ set goals themselves, and 54.0 percent $(n=29)$ indicated that they shared group goal setting with group members. Parents determined goals for 13.0 percent $(n=7)$; teachers for 17.0percent ( $n=9)$; the individualized education plan (IEP) team determined goals for 18.5 percent $(n=10)$ of the respondents. Clearly the school social workers in this study were using a team approach in their group goal setting. $<$ bh $>$ Practice Evaluation

Respondents were asked to check off the methods they used to record their groups from a list of possibilities. An interesting picture emerged. Of the respondents, 31.5 percent ( $n=$ 17) recorded their groups in the individual file for each student. Another 28.0 percent ( $n$ $=15)$ kept records by group, 37.0 percent $(n=20)$ kept general records for all their groups, 8.0 percent $(n=4)$ did not keep any records of groups. Respondents also suggested some creative strategies for recording groups, including keeping track of groups in a daily log and asking students to keep their own records. Several also indicated that they keep notes in students' IEP files. Respondents could indicate more than one kind of recording, and clearly some were using several different recording strategies.

On an open-ended question school social workers indicated that they use a wide variety of ways to evaluate the success of their groups, including pre-and posttest surveys, observations of behavior, IEP goals, teacher checklists, number of discipline referrals, number of outbursts, attendance, grades, and student self-reports. Only one respondent did not respond to the question about measuring the success of groups. By far 


\section{Group Outcomes 9}

the largest category of responses was feedback from adults in students' environments, including teachers (25 responses), administration (three responses), school staff (two responses), and parents (13 responses). This information about member accomplishments resulting from group participation took the form of observation reports, feedback, and behavior rating scales. Student self-reports were used by 22 respondents. Three additional school social workers indicated that they used student surveys to measure results; one of these indicated the use of a comparison pretest. Respondents gave 14 examples of monitoring success through the use of specific, measurable goals. For instance, they used goals from students' IEPs, attendance records, grades, number of disciplinary referrals, frequency of helpful comments made in the group, and tests of the knowledge being shared in the group.

Eight of the respondents indicted that they personally observed change in their members. One person reported the use of role-play in the group to monitor success. Another reported the use of records to note member change over the course of the group.

Respondents also indicated that they used more subjective means of identifying success in individual members. For example, they mentioned motivation, positive and negative changes in behavior, helpful comments made in the group, subjective individual evaluations, and observation of student attitudes.

Like the tendency noted earlier to focus on individual behavior rather than group dynamics, there were few indications that success of groups was determined in terms of group processes. There were, however, several comments suggesting that respondents felt their groups were more successful if students indicated that they were attracted to the group. These comments included the following: members coming on time to group, a low 
number of drop outs from groups, "if kids ask to come to group," and group evaluations. Some respondents also evaluated the success of their groups by noting group process issues: compatibility, trust, member rapport, apparent "closeness and caring" of members, and increased social inclusion.

When asked in a yes/no question, slightly fewer than half (44.0 percent, $n=24)$ of the social workers indicated that others in their school districts checked on the success of their groups. Apparently there is some awareness of practice accountability on the part of others besides the school social worker, but that external accountability is far from universal.

$<$ ah $>$ Discussion

Extreme caution must be taken in interpreting the findings of this study. In addition to the small sample size, it is possible that school social workers who are members the School Social Workers' Association of America are not representative of all school social workers. The results cannot be generalized. Nevertheless, the findings provide the beginnings of a fruitful discussion about practice evaluation and increased understanding of evaluation of school-based group work.

It appears that most school social workers in this sample were, in fact, evaluating the outcomes of their groups. More than 70 percent were doing so, but more than 25 percent were not. When they did evaluate their group work outcomes, school social workers often assessed by individual members' goals. Very few of the respondents were using specific, measurable outcomes to monitor the success of their groups.

School social workers in this sample rarely identified group dynamics and processes such as social interaction and mutual helping as qualities they wished to see in 
a successful group. This finding indicates that Sabatino and Timberlake's (1999) advice to school social workers and Northern and Kurland's (2001) recommendations to group workers to monitor processes of intervention to determine what causes changes in client outcomes have not yet successfully encouraged school social workers to monitor the processes that lead to client change.

The finding that record keeping is often done by group rather than by individual records is complicated by the finding that goals are generally determined for individuals rather than for the entire group. If records are kept by group, and goals are monitored individually, record keeping is out of step with documentation needs. Even though the NASW Standards for School Social Work Services (2002) mandate keeping adequate data to monitor practice, only one respondent indicated that he or she was doing so.

Use of specific, measurable goals occurred much less frequently than subjective evaluations, including informal observation, feedback from other adults, student reports (rarely written), assessment of closeness and caring, and observation of attitudes. The use of single-system designs and goal-attainment scaling to measure outcomes was apparently nonexistent in this sample. These findings are compatible with the conclusions of Gerdes and colleagues (1996) and Ventimiglia and colleagues (2000) that social workers are using more subjective and pragmatic efforts than objective methods to evaluate their practice.

There is a disparity between recommendations in the literature for monitoring group work practice in school settings and the reality of outcome evaluation as practiced by school social workers. On the basis of these discrepancies, School social workers 
should find efficient ways to improve their monitoring of group work outcomes. Specifically, they should:

- identify measurable goals and be certain that the goals are monitored consistently

- use goal-attainment scaling and single-system designs that would great augment their evaluations;

- avoid using group records to evaluate individual members (Because goals are generally developed for individual group members rather than for groups as a whole, keeping group records is contraindicated. When goals are monitored for individuals, individual records should be used to track them;

- make greater use of existing data (that is, attendance records, test scores, grades, discipline reports) readily available in student records to monitor school-based group goals;

- articulate and report case studies and subjective impressions of student change to supplement reports of quantifiable goals

- link descriptions of the change process, specifying group interventions and group dynamics along with outcome reports to determine what interventions are effective.

There is a need for more research on the way school social workers are monitoring their group work practice, beginning with a larger study with a more complete sample to overcome the limits of the current study. More research also should determine how social workers are monitoring group dynamics and how those dynamics relate to positive change in member goals. In addition, further exploration should uncover ways to integrate measurable, specific outcome evaluation into the busy schedules of school 
social workers. The field could also benefit from new ways to record groups so as to be able to track individual goals and group dynamics more efficiently.

Although many school social workers are evaluating their group work practices, most are evaluating individual performance using subjective means. Few are identifying positive group dynamics as foci for their evaluation efforts. The use of specific, measurable means of monitoring attitudes and behaviors needs to be greatly improved, as does understanding of the group processes that produce positive change. Given the push to produce measurable outcomes in school settings, the frequent need to justify services to school boards funding these services (Franklin, 1999), and the ethical mandate to be certain that social work practice is effective (Allen-Meares et al., 2000), school social workers need to be more specific in monitoring both the processes and outcomes of their group work practice. Perhaps even greater is the challenge to find the time and energy to accomplish these evaluation tasks. If, however, school social workers do not take the lead in finding measurable ways to evaluate their practice and communicate results to administration, boards, and parents, others outside the profession are likely to do it for them, using their own definitions, goals, and research designs. It is imperative, therefore, that school social workers take the opportunity and use their own voices to document the worth and value of this important social work methodology. $<$ dgbt $>$

\section{$<$ ah $>$ References}

Allen-Meares, P., Washington, R. O., \& Welsh, B.L. (2000). Social work services in schools. Boston: Allyn \& Bacon

Feldman, R. A. (1985). Evaluating group work interventions. In M. Sundell, P. Glasser, R. Sari, \& R. Vinter (Eds.), Individual change through small groups (pp. 350367). New York: Free Press. 
Franklin, C. (1999). Research on practice: Better than you think? Social Work in Education, 21, 3-9.

Gerdes, K. E., Edmonds, R. M., Haslam, D. R., \& McCartney, T. L. (1996). A statewide survey of licensed clinical social workers' use of practice evaluation procedures. Research on Social Work Practice, 6, 27-39.

Kaminer, Y., Blitz, C., Burleson, J. A., Kadden, R. M., \& Rounsaville, B. J. (1998). Measuring treatment process in cognitive-behavioral and interactional group therapies for adolescent substance abuse. Journal of Nervous and Mental Disease, 186, 407-413.

McCullagh, C. E., \& Koontz, B. A. (1993). A self-report questionnaire for group work: Monitoring the outcome of group work intervention with special education students. Iowa Journal of School Social Work, 6(3), 5-19.

Magen, R. H., \& Glajchen, M. (1999). Cancer support group: Client outcome and the context of group process. Research on Social Work Practice, 9, 541-554.

National Association of Social Workers. (2002). NASW standards for school social work services. Washington, DC: Author.

Northern, H., \& Kurland, R. (2001). Social work with groups. (3rd ed.) New York: Columbia University Press.

O’Brien, W. H., Korchynsky, R., Fabrizio, J., McGrath, J., \& Swank, A. (1999). Evaluating group process in a stress management intervention: Relationships between perceived process and cardiovascular reactivity to stress. Research on Social Work Practice, 9, 608-630.

Rice, A. H. (2001). Evaluating brief structured group treatment of depression. Research on Social Work Practice, 11, 53-78.

Rose, S. D. (1984). Us of data in identifying and resolving group problems in goal oriented treatment groups. Social Work with Groups, 7(2), 23-36.

Sabatino, C. A., \& Timberlake, E. M. (1999). Research in school social work: Catching up and moving on. In R. Constable, S. McDonald, \& J. P. Flynn (Eds.), School social work: Practice, policy, and research perspectives (4th ed., pp. 538-558). Chicago: Lyceum Press.

Shulman, L. (1992). The skills of helping individuals, families, and groups. Itaska, IL: F. E. Peacock.

Toseland, R. W., \& Rivas, R. F. (2001). An introduction to group work practice. (4th ed.). Boston: Allyn \& Bacon. 
Ventimiglia, J. A., Marschke, J. M., Carmichael, P., \& Loew, R. (2000). How do clinicians evaluate their practice effectiveness: A survey of clinical social workers. Smith College Studies in Social Work, 70, 287-306.

Yalom, I. D. (1995). The theory and practice of group psychotherapy. (4th ed.). New York: Basic Books.

<author's blurb > Kendra J. Garrett, DSW, is associate professor, School of Social Work, College of St. Catherine and University of St. Thomas, LOR 406, 2115 Summit Avenue, St. Paul, MN 55105; e-mail: kjgarrett@stthomas.edu.

Accepted March 9, 2005 